\title{
Influence of salinity stress on growth parameters, photosynthetic activity and cytological studies of Zea mays, L. plant using hydrogel polymer.
}

\author{
Hameda El Sayed Ahmed El Sayed \\ Department of Biology, Faculty of Applied Science for Girls, University of Umm Al Qura, \\ Makkah Al Mukaramah, Kingdom of Saudi Arabia.
}

e. mail: Heelsayed@uqu.edu.sa and D.Hameda@hotmail.com

\begin{abstract}
The effects of incorporating a hydrogel polymer with sand on development of selected maize (Zea mays, L.) grown under saline conditions has been demonstrated. The seeds of maize was germinated in sand/swollen hydrogel polymer mixture (80:20 v/v) with added Hoagland nutrient solution, then transplanted after 7 days from germination into a range of sand/swollen hydrogel polymer $(90: 10 \mathrm{v} / \mathrm{v})$ in plastic growbags. Saline solutions containing $\mathrm{NaCl}, \mathrm{CaCl}_{2}, \mathrm{mgCl}_{2}(0.0$, $2,000, \quad 4,000, \quad 6,000, \quad 8,000 \mathrm{ppm}$.)were applied to the growbags (to field capacity twice per week, alternating with a comparable watering regime. Polymer incorporating with sand reduced the effect of salinity treatments. Maize (Zea mays, L.) adapted to salinity (<8,000 ppm) was found to have undergone extensive osmotic adjustment by accumulation of organic and inorganic solutes. With the exception of $2,000 \mathrm{ppm}$, salinity decreased seed germination, plant growth yield production and mitotic division. With salinity treatment the water content tended to increase more in the root with salinity treatment, but succulence was greater in shoot than root. Total pigments (chlorophyll $a+b$ \& carotenoids) and photosynthetic activity decreased with salinity treatments. The results indicate that adaptation of maize plant to salinity stress had occurred; may make significant contributions by using hydrogel polymer to improve the soil characters and adapted the maize plant to salinizations.
\end{abstract}

Keywords : maize, Hydrogel Polymers, $\mathrm{NaCl}, \mathrm{CaCl}_{2}, \mathrm{MgCl}_{2}, \mathrm{Growth}$, Chloroplast Pigment, Photosynthetic Activity, Cytological Studies.

\section{Introduction}

The potential use of hydrogel polymers as soil conditioners or substrates for plant growth depends on a number of factors including their capacity to swell in water or water vapor, release of the contained moisture from the hydogel to the plant roots, the partitioning, binding and release of ions nutrients. Hydrogels which are commercially available and advocated for use as soil conditioners include cross linked acrylic copolymers such as polyacrylamide or polyacrylic acid and insolebilised starch. The hydrogel polymer used in this study is based on poly (ethylene oxide), a material widely used in industry and pharmacy in the forms of poly (ethylene glycol) and non ionic surface active agents. Poly (ethylene glycols)of high molecular weight are water soluble but can be converted into water insoluble and swell able hydrogels via the reaction of their hydroxylic end groups with diisocyanates with or without the addition of other polyols as cross linking agents. The crosslinking can be by urethane, urea, allophanate or biurel group. The formation of polyurethane hydrogel is shown below:

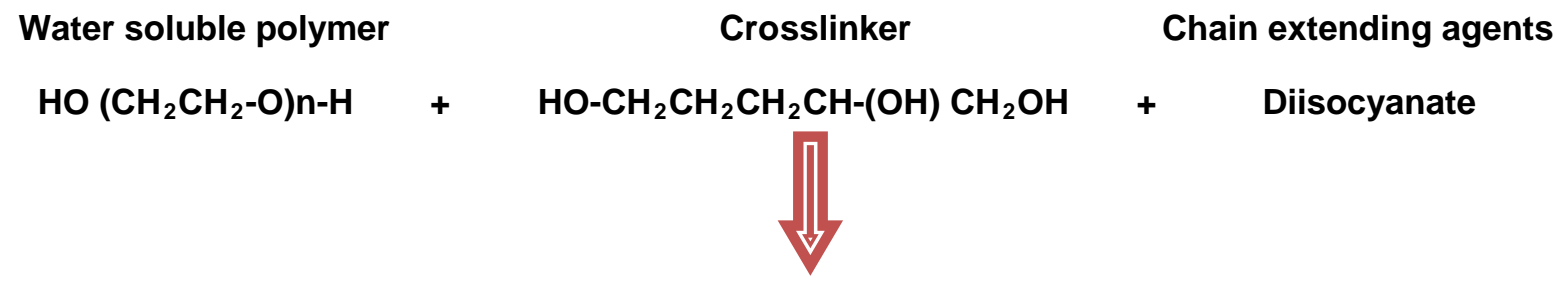

Crosslinked Pol (ethylene Oxide) Co-polyurethane hydrogel 
These products absorb and hold water and are of interest as potential aids to arid land plant production (Graham, 1982). El Sayed, et al., (1991) \& (1995) and El Sayed and Kirkwood (1992) observed that a high salinity conditions were reduced the growth but appeared to be tolerant at all levels of hydrogel polymer incorporation with sand (sand/swollen hydrogel polymer v/v).

Soil salinity may be defined as any accumulation of soluble salts may be harmful to plants (Bernstein, 1974). Generally, saline soils are found in arid and semi-arid regions, where the salts formed by the weathering of soil minerals are not fully leached and high evaporation rates result in accumulation of salts. In higher plants, salt tolerance may be achieved through the preferential accumulation of compatible osmotic solutes in the cytoplasm (Flowers, et al., 1977) in order to maintain equilibrium of the water potential of vacuole and cytoplasm (Stewart and Lee, 1974; Storey and Wyn Jones, 1975). Salinity treatments are known to increase the concentration of sugars, organic acids, amino acids including proline and protein. Accumulation of chlorophyll a seems to be related to the neutral $\mathrm{pH}$ of the cell sap in plants of saline habitats and to the formation of sodium complexes cadaverine and putrescence. In addition salts increase the activity of oxidative enzymes which also favours the biosynthesis of pigments (Strogonov, 1970). Increased salinity appears to reduce the level of potassium uptake by plants. Ayers and Eberhard (1960) found that increasing the concentration of sodium and calcium in soil resulted in a moderate decrease of potassium in the same order of magnitude for plants both broad bean and green bean plants. Uptake and accumulation of $\mathrm{mg}^{2+}$ and $\mathrm{Na}^{+}$is increased by saline conditions (Samenia, et al., 1980), while accumulation of chloride may be localized in the plant (Hajrasuliha, 1980). The dry matter and water contents of $\mathrm{E}$. paralias varied greatly by nitrogen deficiency under salinity, while proline initiator had low effect. Salinity combined with nitrogen deficiency promoted achieving high water and dry matter contents especially 50-150 mM which could be a result of the leaves osmotic regulations. Salinity enhanced increases in leaves OP as has frequently been recorded by many authors, e.g. Flowers et al. (1977) and Greenway and Munns (1980).

Salinity is Known to retard plant growth through its influence on several facets of plant metabolism including osmotic adjustment (e.g. Bernstein, 1963), ion uptake (e.g. Greenway, et al., 1966), enzyme activities (e.g. Weimberg, 1970), protein and nucleic acid synthesis (e.g. Nieman, 1965), photosynthesis (e.g. Downton, 1977) and hormonal balance (e.g. Itai, et al., 1968). Although much work has been done on the effect of salinity on various aspects of crop plant growth and development, little information is available regarding salt tolerance of bean (Vicia faba, L.). Metabolic studies in chloroplasts from salt stressed plants of peanut performed by Sanjeeva, (1967) revealed the sensitive nature of the plant. Several workers have noticed a decrease in net photosynthetic rate due to salt stress (e.g. Strack, et al., 1975). According to Nieman and Clark (1976) this is mediated through the effect of salinity on photophosphorylation. Salinity is reported to affect the strength of the forces binding the complex of pigment-protein-lipid in the chloroplast structure (Strogonov, 1970). The salinity of irrigation water as a cause of yield reduction has been the subject of many investigations. The salinity effect seems to depend also on other factors such as soil properties, climate, cultural practices and water management. Whereas many data are available with regard to the effect of salinity on crop yield, a great deal less is known about the physiological processes during growth. The salinity effect on the water stress of the plant, its gaseous exchanges and its metabolism has been analyzed over short periods (see for example Osmond and Greenway, 1972; Longstreth and Strain, 1977; Albuzio, 1978; Yeo, et al., 1985; West, et al., 1986; Bowman and Strain, 1987).

Kaymakanova, and Stoeva, (2008) found the physiological responses of three different bean cultivars plants were treated for 7 days with $\mathrm{NaCl}$ and $\mathrm{Na}_{2} \mathrm{SO}_{4}(100 \mathrm{mM})$, starting at the appearance of the first trifoliate leaf unfolded. It was established that the applied dose of both salt types caused stress in the young bean plants, which found expression in the suppression of growth and photosynthesis activity. The bean cultivars showed different reaction to salinity and the type of salt. It was evident that cv. Lody was most sensitive to salt stress. The applied $\mathrm{Na}_{2} \mathrm{SO}_{4}$ caused stronger inhibition in all cultivars than those treated with $\mathrm{NaCl}$. The amount of proline in the tissues of the salt-treated plants increased, while the cell water potential was reduced.

In this paper, the ability of maize (Zea mays, L. cv. Giza 129) to accumulate potential osmotic solute in response to osmotic stress has been examined, particularly in relation to the accumulation of organic and inorganic solutes under using hydrogel polymer as a soil conditioner. 


\section{MATERIAL AND METHODS}

Hydrogel polymer : At ambient temperature the water - holding capacity of the material used in this study was $9.7 \mathrm{~g} / \mathrm{g}$ of dry hydrogel polymer. The initially dry granules had a particle size of $0.5-2.0$ $\mathrm{mm}$ and when fully swollen were rubbery grains through which liquid water could still freely drain. Typical preparations of poly (ethylene oxide)-copolyurethane hydrogels have been reported previously (Graham, 1982).

Salinity Treatments: The grains of maize (Zea mays, L. cv. Giza 129), were obtained from the Ministry of Agriculture, Egypt. In separate glasshouse experiments carried out in late spring under controlled light and temperature conditions (14 hr light, $25^{\circ} \mathrm{C}$ day $/ 15^{\circ} \mathrm{C}$ night), the gains of maize were germinated in sand/swollen polymer mixture $(80 / 20$ v/v) with added Hoagland's nutrient solution. After 7 days from germination, three plants were transplanting into polythene growbage pots $(25 \mathrm{~cm} \mathrm{x}$ $35 \mathrm{~cm}$ ) containing a range of sand/swollen hydrogel polymer combination $(90 / 10, v / v)$ in the greenhouse. Saline solutions containing $\mathrm{NaCl}, \mathrm{CaCl}_{2}, \mathrm{mgCl}_{2}$ as molar solutions were applied to produce final concentrations of $0.0,2,000,4,000,6,000,8,000$ ppm. (Molar equivalents $0.0,0.6 \times 10^{-1}, 1.2 \times 10^{-1}$, $1.8 \times 10^{-1}$, \& $2.4 \times 10^{-1}$ respectively. Hoagland solution being used as control. The treatment were applied twice a week alternating with watering the plants with equal amounts of water to compensate for the evapo-transpiration of water and avoid excessive salt accumulation in the plant. Harvesting was carried out at the vegetative, flowering and fruiting stages and the effect of treatment analyzed by evaluation of growth parameters, water content, pigments, photosynthetic activity, yield production, organic and inorganic components. The data for fruiting stage was only presented in this paper.

Grain Germination: Grains of Maize (Zea mays, L. cv. Giza 129) were germinated at $28^{\circ} \mathrm{C}$ in dark in 9 $\mathrm{cm}$ glass Petri dishes on disc of filter paper (Whatman No.1) moisted with appropriated salinity culture solutions.

Growth and Succulence: At harvest the Maize (Zea mays, L. cv. Giza 129) plants of were washed with distilled water, blotted thoroughly and the plant divided into root and shoot, to measure the shoot height, root depth,(cm/shoot or root), shoot and root dry weights (D.W.) were resulted and succulence determined (Succulence $=$ F.W. $/$ D.W $)$.
Yield Production: The economic yield was assessed as weight of grain and straw per pot and the harvest index per plant calculated.

Chloroplast Pigment Analysis: An $85 \%$ aqueous acetone extract of a known F.W. of leaf was assayed Spectrometrically (LKB NOVASPEC) at 664, 645, $420 \mathrm{~nm}$ (Metzner, et al., 1965). The following equations were used to determined the concentration of the pigment fractions as $\mathrm{\gamma} / \mathrm{ml}$.

$$
\begin{aligned}
& \text { Chlorophyll } a=10.3 E_{664}-0.918 E_{645} \\
& \text { Chlorophyll } b=19.7 E_{645}-3.870 E_{664}
\end{aligned}
$$

Carotenoids $=403 \mathrm{E}_{452}-(0.0264 \mathrm{Chl} . \mathrm{A}+0.426$ Chl. b).

\section{The pigment fractions were calculated as $\mu \mathrm{g}$ Chl./mg D.W.}

Photosynthetic Activity: Chloroplasts were prepared by the method of Aronoff (1949) and Osman, et al., (1982). Fresh leaves were shredded, ground for one min in a blender, using a buffered solution of $0.4 \mathrm{M}$ sucrose, $20 \mathrm{mM}$ HEPES-KOH $(\mathrm{pH}$ 7.8), $3 \mathrm{mM} \mathrm{MgCl}_{2}, 4 \mathrm{mM}$ sodium ascorbate and $0.1 \%$ bovine serum albumin (BSA) (Osman et al., 1982). The much was strained through cheese-cloth, filtered and the suspension centrifuged ( $1 \mathrm{~min}$ at $8,000 \mathrm{X} \mathrm{g}$ ). The pellet was re-suspended in the isolation medium, centrifuged ( $5 \mathrm{~min}$ at $300 \times \mathrm{Xg}$ ) and the supernatant re-centrifuged (10 $\mathrm{min}$ at $1,000 \times \mathrm{g}$ ). The sediment was re-suspended in a $2 \mathrm{ml}$ buffer solution at $\mathrm{pH} 6.8$ and the aggregates dispersed. The levels of chlorophyll a \& chlorophyll b were determined by the method described by Mackinney (1941). An aliquot of $0.2 \mathrm{ml}$ of the chloroplast suspension was extracted with $3.8 \mathrm{ml}$ of $85 \%$ cold aqueous acetone and the density of the extract measured at $652 \mathrm{~nm}$. The chlorophyll content was calculated according to the following equation :

$\mathrm{C}=\mathrm{E} 652 \times 1,000 / 34.5 \mathrm{mg} \mathrm{chl} . / \mathrm{L}$

\section{Where $\mathbf{c}=$ chlorophyll $\mathbf{a} \& \mathbf{b}$}

The photosynthetic activity of the isolated chloroplsts was measured using potassium ferricyanide $(5 \times 10$ $4 \mathrm{M})$ as an electron acceptor. Reduction of ferricyanide was monitored Spectrophotometrically ( $L K P \quad N O V A S P E C$ ) at $420 \mathrm{~nm}$ at room temperature. The reduction mixture contained $0.2 \mathrm{ml}$ 
of chloroplast suspension, $\left(0.2-0.8 \mathrm{mg} \mathrm{chl} \mathrm{ml}^{-1}\right)$, $3.8 \mathrm{ml}$ HEPES buffer $(\mathrm{pH} 7.8)$, and $5 \times 10^{-4} \mathrm{M}$ potassium ferricyanide. The mixture was illuminated at $300 \mathrm{Wm}-2$ using a slide projector provided with a heat filter with a $24 \mathrm{v}, 250 \mathrm{w}$ quartz halide bulb, 15-45 $\mathrm{cm}$ from the well. The photosynthetic activity of the isolated chloroplasts was calculated from the standard curve and expressed as $\mu \mathrm{mol}$ fericyanide $\mathrm{mg} \mathrm{chl}^{-1} \mathrm{~h}^{-1}$ (Arnon and Shavit, 1963).

Cytological Preparations: Following each treatment, root tips were detached and fixed in a freshly prepared solution of $3: 1 \mathrm{v} / \mathrm{v}$ absolute ethyl alcohol and glacial acetic acid. Roots were kept in this fixative for $24 \mathrm{hr}$, after which they were transformed into $70 \%$ ethyl alcohol and stored in a refrigerator. Cytological preparations were carried out on treated root tips using the Feulgen Squash Technique. Root tips of maize were washed in distilled water, hydrolyzed in $1 \mathrm{~N} \mathrm{HCl}$ at $60^{\circ} \mathrm{C}$ for 12 min, washed in distilled water and then transferred to the staining Feulgen reagent for $2 \mathrm{hr}$. The deeply stained root tips were tested out on clean slides and squashed in a drop of $45 \%$ acetic acid. The slides and cover slips were separated by rinsing in a $50 \%$ ethyl alcohol or by using the carbon dioxide ice method. The preparations were dehydrated in a series of $50,70,95 \%$ and absolute alcohol for three min in each solution, followed by rinsing in a mixture of absolute alcohol and xylene for 5 min and finally in three changes of xylene. Preparations were made permanent by mounting in Canada Balsam or Eupharal.

Cytological Studies: For the cytological investigation, at least six slides of each treatment were examined (H.P.) to determine the rate of mitotic division (Mitotic Index, M.I.)and the frequency of mitotic phases. The same slides were analysed for mitotic and chromosomal abnormalities produced by the applied salinity treatments.

The mitotic index (M.I.) was calculated using the following formula:

\section{M.I. = number of dividing cells in all phases of mitosis $\times 100$ Number of dividing cells in all stages of mitosis}

Six slides were examined and the proportion of the different stages of mitotic division calculated as a percentage of total cells and the phase index
(Ph.I.) for each stage was calculated using the following formula;

Ph.l. = number of cells in a particular mitotic stage $\times 100$ Number of dividing cells in all stages of mitosis

The abnormalities were classified into the following types, C-metaphase, C-anaphase, polyploidy, multipolar anaphase and telophase, chromosome lagging, chromosomal bridges, breakage, chromosomal stickiness, and micro-nucleated and multinucleated cells.

Statistical Analysis: Where relevant, the experimental data was subjected to analysis of variance. Percentage values were transformed into arcsines according to Bliss (1937) and analysis of variance was carried out according to Snedecor and Cochran (1967).

\section{RESULTS AND DISCUSSION}

Grain Germination Percentage; Growth and Succulence: Salinity treatments increasingly reduced germination of maize (Zea mays, L.) with increasing salinity concentrations (Fig. 1). The effects of incorporating a hydrogel polymer into sand on development of maize (Zea mays, L.) grown under saline conditions has been observed the increasing of grain germination by Sand/Hydrogel polymer (SS/HP) than pure sandy soil (SS). Sayed, et al., (1991) \& (1995) and El Sayed and Kirkwood (1992) observed that a high salinity conditions were reduced the growth but appeared to be tolerant at all levels of hydrogel polymer incorporation with sand (sand/swollen hydrogel polymer $\mathrm{v} / \mathrm{v}$ ). Sensitivity to salinity treatments was shown by maize (Zea mays, L.) from the earliest stage of development, germination rate and percentage were reduced by all salinity concentrations. These results confirm earlier finding that germinating rate and capacity of maize were delayed with increasing salinity of substrates 
(Maliwal, et al., 1975). Kaymakanova, and Stoeva, (2008) found the reduction of the biomass in beans under saline condition was indicative of several growth limitations, so, the salinity had adverse effects not only on the biomass, but also on other morphological parameters such as plant height, number of leaves, root length and shoot/root ratio.
Some authors reported that in Phaseolus vulgaris salinity reduced shoot and root weights (Brougnoli and Lauteri, 1991; Gamma, et al., 2007). The statistical analysis (One, two, and three - Way analysis of variance (ANOVA) as shown in Appendix Table (1).

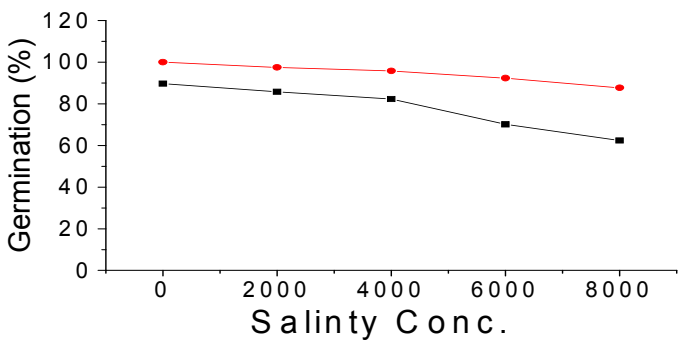

Shoot height and root extension were reduced by salinity treatments at concentration of $4,000 \& 6,000$ $\mathrm{ppm}$ respectively in pure sandy soil (SS) but increased in shoot height and root extinction with sand/hydrogel polymer (SS/HP) (v/v) (Fig. 2 a \& b). Salinity is one of the most important a biotic stress factors limiting plant growth and productivity (Khan and Panda, 2008). Salinity affects almost every aspect of the physiology and biochemistry of plants and significantly reduces yield. High exogenous salt concentrations affect seed germination, water deficit, cause ion imbalance of the cellular ions resulting in ion toxicity and osmotic stress (Khan, et al. 2002; Khan and Panda, 2008). Generally, shoot and root dry weight decreased with salinity treatments with the exception of $6,000 \& 8,000 \mathrm{ppm}$ treatments which

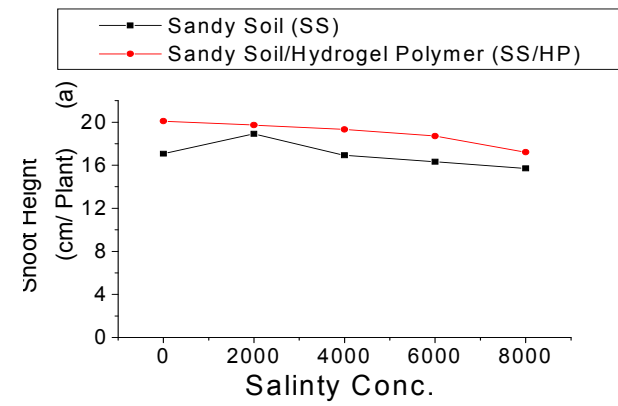

Fig. (1) : Effects of Hydrogel Polymer Incorporating With Sand (SS/HP - "v/v") and Pure Sandy Soil (SS) On Grain Germination (\%) Of Selected Maize (Zea mays, L.) Plant Under Saline Conditions.

decreased shoot dry weight in pure sandy soil (SS) but increased shoot and root dry weight with sand/hydrogel polymer (SS/HP) (v/v) (Fig. 2 c\&d). Generally, shoot and root dry weight decreased with salinity concentration and this has been attributed mainly to the effect of water deficits (e.g. TaleisnikGertel, et al., 1983). Shoot succulence decreased with salinity treatments, whereas, root succulence increased except at $8,000 \mathrm{ppm}$ in pure sandy soil (SS) but increased in case of sand/hydrogel polymer (SS/HP) (v/v) (Fig. 3). Growth suppression seems to be a non specific effect of salt, depending more on the total concentration of soluble salts than on species ions (e.g. Maas and Nieman, 1978). The statistical analysis (One, two, and three - Way analysis of variance (ANOVA) as shown in Appendix Table (1).

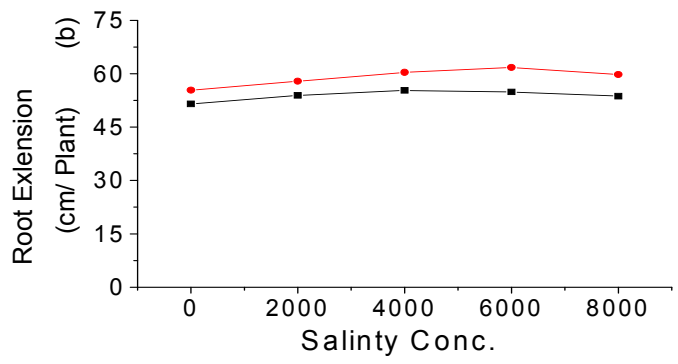

Fig. (2 a \& b) : Effects of Hydrogel Polymer incorporating with Sand (SS/HP - "v/v") and Pure Sandy Soil (SS) On (a) Shoot Height and (b) Root Extension (cm/Plant) Of Selected Maize (Zea mays, L.) Plant Under Saline Conditions. 
Agric. Biol. J. N. Am., 2011, 2(6): 907-920
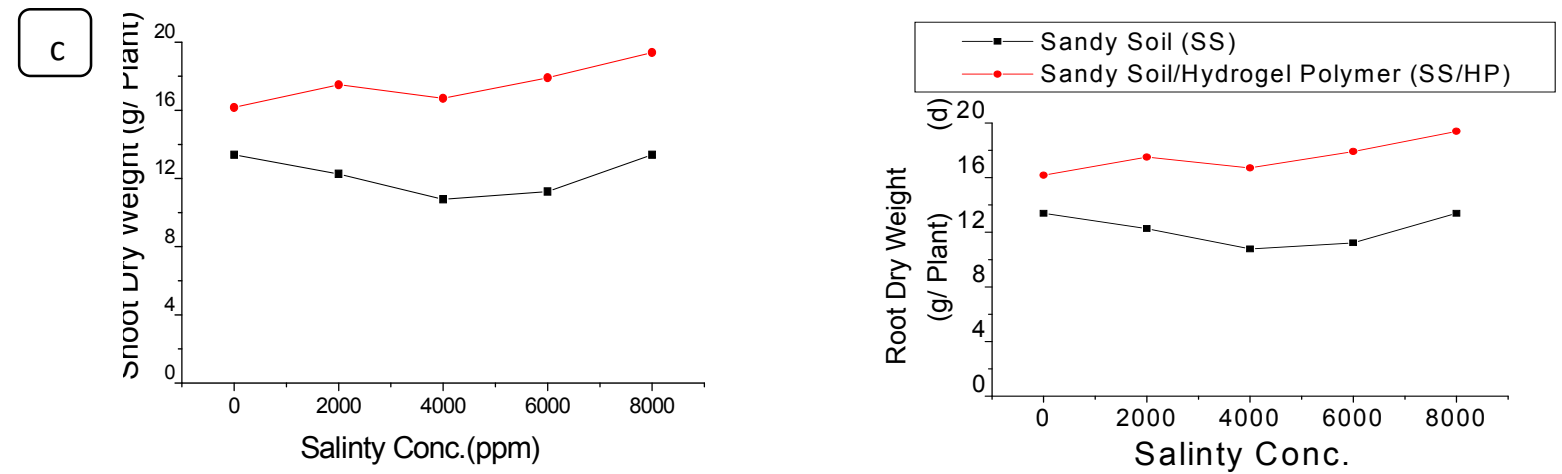

Fig. (2 c\&d) : Effects of Hydrogel Polymer incorporating with Sand (SS/HP - "v/v") and Pure Sandy Soil (SS) On (c) Shoot and (d) Root Dry Weight (g/Plant) Of Selected Maize (Zea mays, L.) Plant Under Saline Conditions.

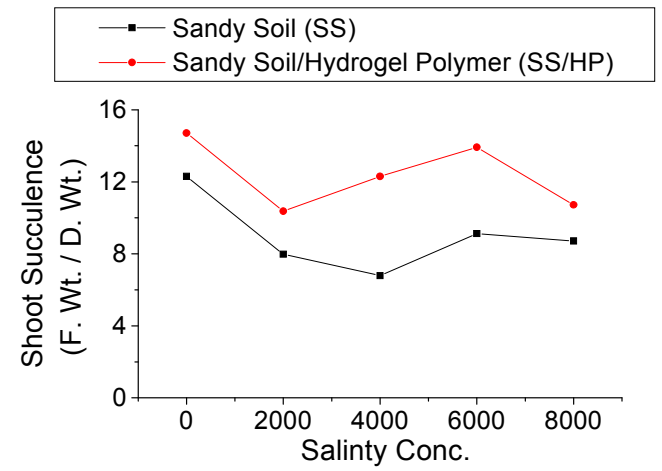

Fig. (3) : Effects of Hydrogel Polymer incorporating with Sand (SS/HP - "v/v") and Pure Sandy Soil (SS) On Shoot Succulence (F. Wt. I D. Wt.) Of Selected Maize (Zea mays, L.) Plant Under Saline Conditions.

Appendix Table ( 1 ): Effects of Hydrogel polymer incorporating with sand (SS/HP - "v/v") and pure sandy soil (SS) on germination percentage, growth and succulence in maize (Zea mays, L.) Plant under satine conditions.

\begin{tabular}{|c|c|c|c|c|c|c|}
\hline I tems & CO & TR & ST & CO/TR & COIST & TR/ST \\
\hline Grain Germination & $*$ & -- & -- & -- & -- & -- \\
\hline Sh. H. \& R. Ex. & $*$ & $* *$ & $* *$ & $*$ & N.S. & $*$ \\
\hline Dry Weight & N.S. & $* *$ & $* * *$ & N.S. & N.S. & N.S. \\
\hline Succulence & N.S. & N.S. & N.S. & N.S. & N.S. & $\star * *$ \\
\hline
\end{tabular}

Statistical treatments, where relevant, the experimental data subjected of One, two, and three - Way analysis of variance (ANOVA).

Note: $F$ values $\quad{ }^{*}=\mathrm{P}<0.05, \quad{ }^{* *}=\mathrm{P}<0.01,{ }^{* * *}=\mathrm{P}<0.001$ and $\quad$ N.S. $=$ Not Significant. CO : Concentrations, TR : Treatments (SS) \& (SS/HP - "V/V"), ST : Stages of growth.

Yield production : With the exception of 2,000 ppm, salinity tended to reduce yield production (weight of grain and straw per pot). The effects of incorporating a hydrogel polymer into sand (SS/HP) on development of maize (Zea mays, L.) grown under saline conditions has been observed the increasing of yield productions by Sand/Hydrogel polymer (SS/HP - "v/v") than pure sandy soil (SS). The harvest index per plant increased at 2,000 \& 4,000 ppm but decreased at $6,000 \& 8,000$ ppm. Salinity treatments $(>2,000 \mathrm{ppm}$ ) decreased yield production (weight of grain and straw per pot) whereas, the harvest index per plant increased with salinity concentration up to $6,000 \mathrm{ppm}$ but incorporating a hydrogel polymer into sand (SS/HP) has been increasing of yield productions, weight of grain, straw per pot and harvest index (Fig.4a,b\&c). A similar results was reported by El Sayed, et al., (1991) \& 
(1995) and El Sayed and Kirkwood (1992) observed that a high salinity conditions were reduced the growth but appeared to be tolerant at all levels of hydrogel polymer incorporation with sand (sand/swollen hydrogel polymer v/v). A similar reduction in yield was reported by Asana and Kale (1965) who detected a 10\% decrease in grain yield of different cultivars of wheat grown under saline conditions; this was due mainly to reduction in 1.000 grain weight. Paliwal, et al., (1976) recorded maximum reductions of $34 \%$ in straw yield and $49 \%$ in grain yield of barley at the highest salt concentration. Reductions in grain and straw yield have also been reported by Abd El Rahman, (1977). The salinity effect on leaf area and dry matter appeared 20 to 40 days later and finally caused a
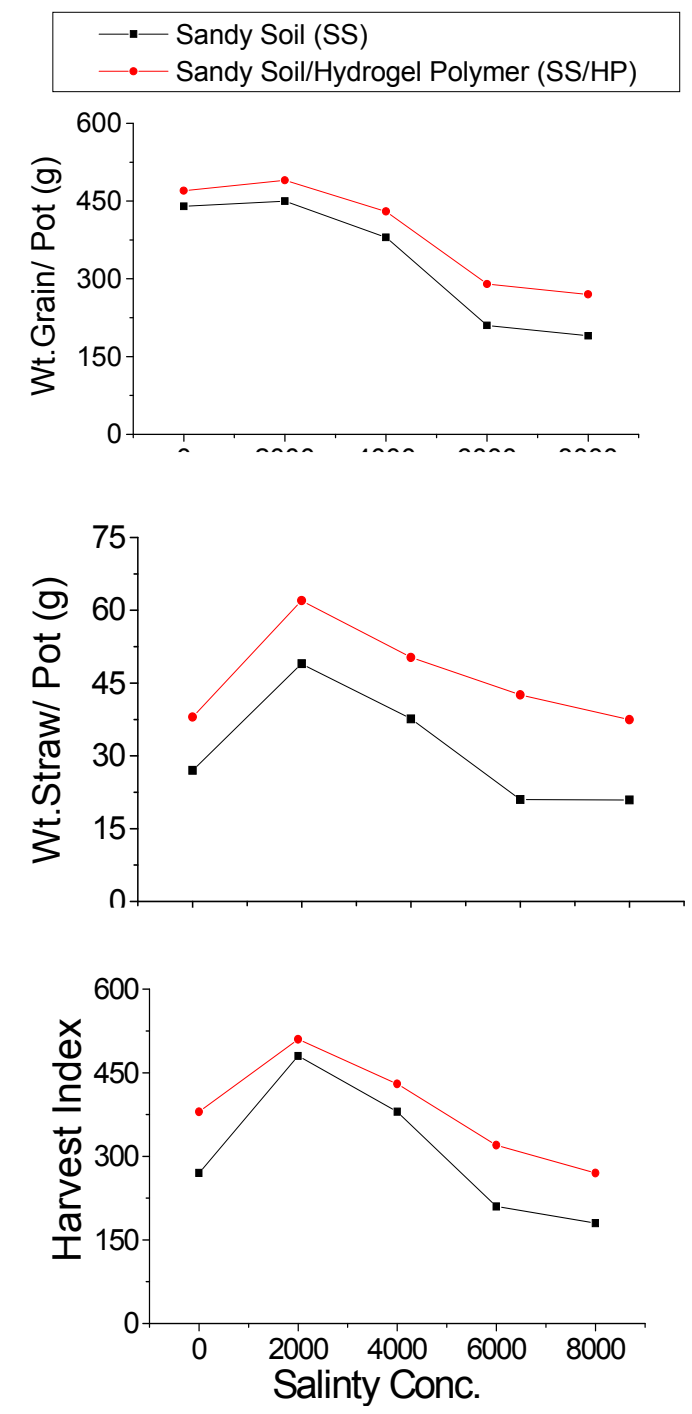

decrease of about $15 \%$. The decrease in yield of grains was about $28 \%$, although the average soil salinity, expressed as ECe, only equalled $2.4 \mathrm{dS} / \mathrm{m}$ for the most saline treatment (Katerji, et al., 1992). The yield depression confirms the low salt tolerance of broad beans (Ayers and Westcot, 1985). The observation that the decrease in yield is mainly caused by a difference in the weight of the grains corresponds with the observation that the water stress was not significantly affected before the stage of flowering and fruit setting. It is possible that the effect of salinity would have been more pronounced if the soil salinity had been different from the start of the experiment (Van Hoorn, 1991). The statistical analysis (One, two, and three - Way analysis of variance (ANOVA) as shown in Appendix Table ( 2 ).

Fig. (4 a) : Effects of Hydrogel Polymer incorporating with Sand (SS/HP - "v/v") and Pure Sandy Soil (SS) On Yield Productions (Weight of Grains/Pot "g") Of Selected Maize (Zea mays, L.) Plant Under Saline Conditions.

Fig. (4 b) : Effects of Hydrogel Polymer incorporating with Sand (SS/HP -"v/v") and Pure Sandy Soil (SS) On Yield Productions (Weight of Straw/Pot "g") Of Selected Maize (Zea mays, L.) Plant Under Saline Conditions.

Fig. (4 c) : Effects of Hydrogel Polymer incorporating with Sand (SS/HP - "vlv") and Pure Sandy Soil (SS) On Yield Productions (Harvest IndexI Plant) Of Selected Maize (Zea mays, L.) Plant Under Saline Conditions. 
Appendix Table (2): Effects of Hydrogel polymer incorporating with sand (SS/HP - "v/v") and pure sandy soil (SS) on Yield production, in maize (Zea mays, L.) Plant under saline conditions.

\begin{tabular}{|c|c|c|c|c|c|c|}
\hline I tems & CO & TR & ST & CO/TR & CO/ST & TR/ST \\
\hline Wt. grains/ pot & N.S. & -- & -- & -- & -- & -- \\
\hline Wt. straw/ pot & $*$ & -- & -- & -- & -- & -- \\
\hline Harvest Index & $*$ & -- & --- & -- & -- & -- \\
\hline
\end{tabular}

Statistical treatments, where relevant, the experimental data subjected of One, two, and three - Way analysis of variance (ANOVA).

Note: $F$ values ${ }^{*}=P<0.05,{ }^{* *}=P<0.01,{ }^{* *}=P<0.001$ and N.S. $=$ Not Significant. CO: Concentrations, TR: Treatments (SS) \&(SS/HP V"/V"), ST: Stages of growth.

Cytological Studies : Cytological studies indicated that the mitotic index decreased with increase in salinity concentration; except at $8,000 \mathrm{ppm}$ (Table. 1). But the effects of incorporating a hydrogel polymer into sand (SS/HP) on development of maize (Zea mays, L.) grown under saline conditions has been observed the increasing of mitotic index by Sand/Hydrogel polymer (SS/HP) than pure sandy soil (SS). The phase index increased with advanced mainly at anaphase and telophase. The reduction in growth may be a decline in the mitotic index with increasing salinity level. but incorporating a hydrogel polymer into sand (SS/HP) has been increasing of mitotic division lead to increased yield productions (weight of grain and straw per pot) and harvest index. A similar results was reported by El Sayed, et al., (1991) \& (1995) and El Sayed and Kirkwood (1992) observed that a high salinity conditions were reduced the growth but appeared to be tolerant at all levels of hydrogel polymer incorporation with sand (sand/swollen hydrogel polymer v/v). Chromosomal abnormalities were observed following salinity treatment during the germination stage and these included polyploidy, c-metaphase, c-anaphase, chromosomal stickiness, lagging chromosomes, chromosome breakage and micronucle; the abnormalities increased with salinity concentration (data not presented) The statistical analysis (One, two, and three - Way analysis of variance (ANOVA) as shown in Appendix Table (3).

Pigment contents and Photosynthetic Activity : The results indicated that the levels of chlorophyll a were always higher than the chlorophyll $b$ or carotenoids; generally pigment levels decreased with salinity treatments (Fig.5a,b\&c). The effects of incorporating a hydrogel polymer into sand (SS/HP) on pigment contents of maize (Zea mays, L.) grown under saline conditions has been observed the increasing of pigment contents by Sand/Hydrogel polymer (SS/HP) than pure sandy soil (SS). Salinity treatments progressively reduced photosynthesis and this was coincident with a decline in leaf chloroplast pigments (chlorophyll a, chlorophyll b and carotenoids). Other workers have concluded that salinity affected the rate of photosynthesis reflecting changes in pigment composition (Ahmed, et al., 1980; Helal and Mengel, 1981; and Berlin, et al., 1982). Photosynthetic activity decreased with increase in salinity concentrations in pure sand soil (SS) but increased with sand/hydrogel polymer (SS/HP) (v/v) (Fig. 5 d).

Table (1) : Effects of Hydrogel Polymer incorporating with Sand (SS/HP - "v/v") and Pure Sandy Soil (SS) On Cytological Studies (Prophase Stage; Metaphase Stage; Anaphase Stage; Telophase Stage and Mitotic Index) Of Selected Maize (Zea mays, L.) Plant Under Saline Conditions.

\begin{tabular}{|c|c|c|c|c|c|c|c|c|c|c|}
\hline \multirow{3}{*}{$\begin{array}{c}\text { (Cytological Studies) } \\
\text { (Stages of Mitotic } \\
\text { Division and Mitotic } \\
\text { Index) }\end{array}$} & \multicolumn{5}{|c|}{$\begin{array}{l}\text { Pure Sandy Soil } \\
\text { (SS) }\end{array}$} & \multicolumn{5}{|c|}{$\begin{array}{l}\text { Hydrogel Polymer incorporating with Sand } \\
\text { (SS/HP - "v/v") }\end{array}$} \\
\hline & \multicolumn{10}{|c|}{ Salinity Concentrations (ppm) } \\
\hline & 0.0 & 2.000 & 4.000 & 6.000 & 8.000 & 0.0 & 2.000 & 4.000 & 6.000 & 8.000 \\
\hline Mitotic Index & 10.2 & 8.0 & 8.7 & 8.8 & 8.0 & 12.3 & 10.7 & 11.3 & 13.9 & 11.0 \\
\hline Prophase Stage & 12.3 & 18.7 & 17.9 & 25.5 & 38.7 & 14.7 & 19.9 & 18.7 & 27.3 & 40.1 \\
\hline Metaphase Stage & 35.0 & 30.7 & 28.9 & 27.2 & 29.7 & 41.0 & 37.8 & 35.1 & 35.1 & 33.8 \\
\hline Anaphase Stage & 38.7 & 33.9 & 35.2 & 33.3 & 25.9 & 41.9 & 40.3 & 49.7 & 40.8 & 39.9 \\
\hline Telophase Stage & 5.7 & 12.3 & 13.7 & 10.9 & 9.8 & 10.8 & 13.9 & 17.8 & 12.1 & 13.7 \\
\hline
\end{tabular}


Appendix Table ( 3 ): Effects of Hydrogel Polymer incorporating with Sand (SS/HP "v/v") and Pure Sandy Soil (SS) On Cytological Studies (Prophase Stage; Metaphase Stage; Anaphase Stage; Telophase Stage and Mitotic Index) Of Selected Maize (Zea mays, L.) Plant Under Saline Conditions.

\begin{tabular}{|c|c|c|c|c|c|c|}
\hline Items & CO & TR & ST & CO/TR & CO/ST & TR/ST \\
\hline Mitotic Index & N.S. & -- & -- & -- & -- & - \\
\hline Prophase & ${ }^{* *}$ & -- & -- & -- & -- & - \\
\hline Metaphase & $*$ & -- & -- & -- & -- & \\
\hline Anaphase & ${ }^{*}$ & -- & -- & -- & -- & -- \\
\hline Telophase & ${ }^{*}$ & -- & -- & -- & -- & -- \\
\hline
\end{tabular}

Statistical treatments, where relevant, the experimental data subjected of One, two, and three - Way analysis of variance (ANOVA).

Note: $\mathrm{F}$ values $*=\mathrm{P}<0.05, \quad * *=\mathrm{P}<0.01, * * *=\mathrm{P}<0.001$ and N.S. $=$ Not Significant. CO: Concentrations, TR: Treatments (SS) \&(SS/HP - "VIV"), ST: Stages of growth.
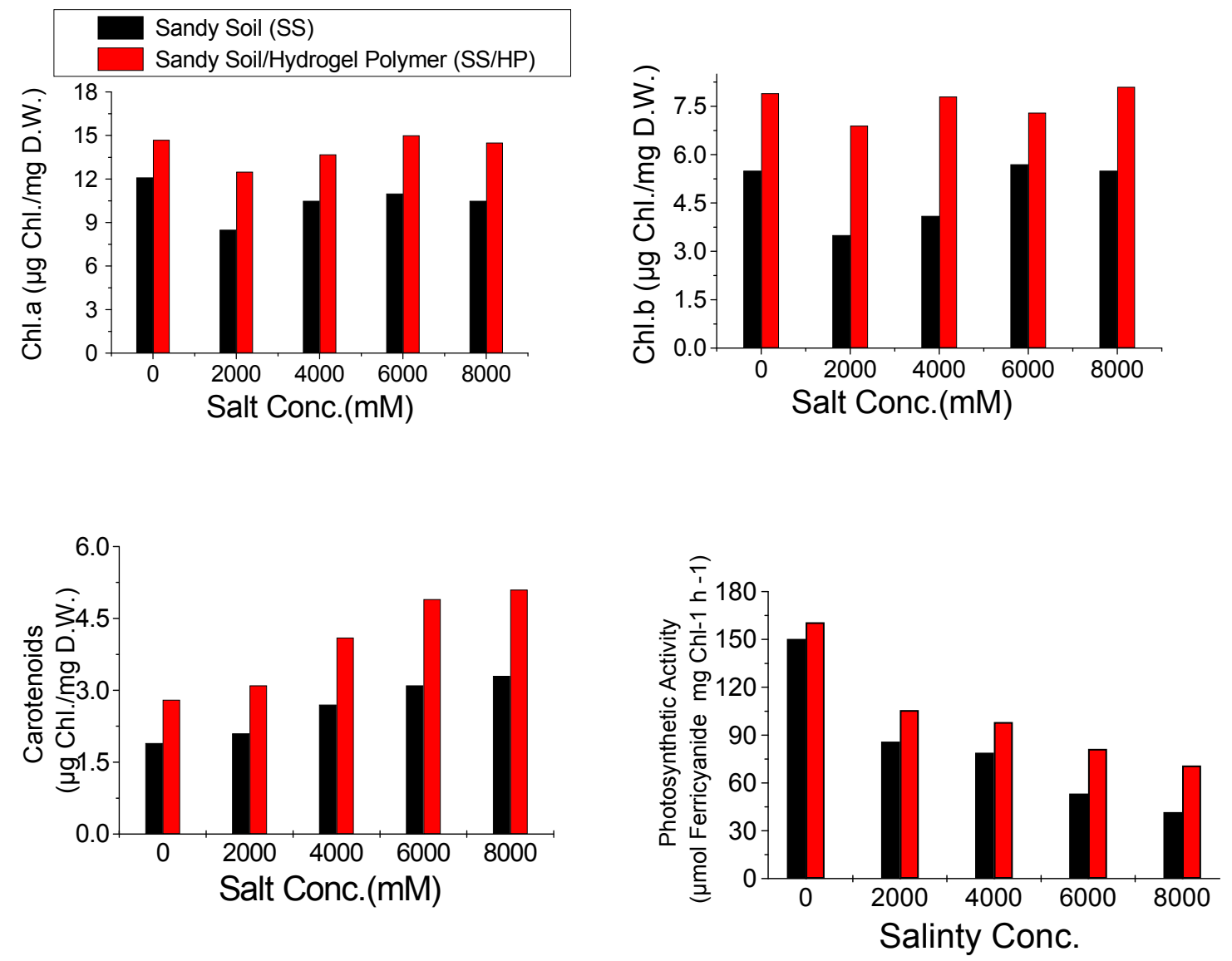

Fig. (5 a, b, c, \& d) : Effects of Hydrogel Polymer incorporating with Sand (SS/HP - "v/v") and Pure Sandy Soil (SS) On (a) Chlorophyll a (b) Chlorophyll b and (c) Carotenoides Contents ( $\mu$ g Chl./mg D.W.) and (d) Photosynthetic Activity ( $\mu \mathrm{mol}$ Ferricyanide $\mathrm{mg} \mathrm{Chl}^{-1} \mathrm{~h}^{-1}$ ) Of Selected Maize (Zea mays, L.) Plant Under Saline Conditions. 
Photosynthetic activity is considerably affected by different of salt for produced no consistent trend. These results agree with those of Gale and Poljakoff-Mayber (1970) who noticed only a small effect of $\mathrm{NaCl}$ treatment (-20 bars) on photosynthetic rate of Atriplex helium while $\mathrm{Na}_{2} \mathrm{SO}_{4}$ reduced it even at 1 bar concentration. Conversely, in corn photosynthesis was found to be more susceptible to $\mathrm{NaCl}$ than $\mathrm{Na}_{2} \mathrm{SO}_{4}$ (Lapina and Bikmu-Khametove, 1972) in barley, wheat and beans, however, there was no significant difference between the effects of $\mathrm{NaCl}$ and $\mathrm{Na}_{2} \mathrm{SO}_{4}$ on photosynthesis (Udovenko et al., 1971). Thus there appears to be a variation in species response in photosynthetic rate to different types of salinities. The most important process that is affected in plants, growing under saline conditions, is photosynthesis. Reduced photosynthesis under salinity is not only attributed to stomata closure leading to a reduction of intercellular $\mathrm{CO}_{2}$ concentration, but also to non-stomata factors. There is strong evidence that salt affects photosynthetic enzymes, chlorophylls and carotenoids (Stepien and Klobus, 2006). Salinity reduces the ability of plants to utilize water and causes a reduction in growth rate, as well as changes in plant metabolic processes (Munnas, 2002). The statistical analysis (One, two, and three - Way analysis of variance (ANOVA) as shown in Appendix Table ( 4 ).

Appendix Table (4 ): Effects of Hydrogel Polymer incorporating with Sand (SS/HP - "v/v") and Pure Sandy Soil (SS) On (a) Chlorophyll a (b) Chlorophyll b and (c) Carotenoides Contents ( $\mu$ g Chl./mg D.W.) and (d) Photosynthetic Activity ( $\mu$ mol Fericyanide mg Chl-1 h -1 Of Selected Maize (Zea mays, L.) Plant Under Saline Conditions.

\begin{tabular}{|c|c|c|c|c|c|c|}
\hline Items & CO & TR & ST & CO/TR & COIST & TR/ST \\
\hline Chlorophyll a & $*$ & -- & ${ }^{* * *}$ & -- & N.S. & -- \\
\hline Chlorophyll b & $*$ & -- & ${ }^{* * *}$ & -- & N.S. & -- \\
\hline Carotenoids & N.S. & -- & ${ }^{* * *}$ & -- & N.S. & -- \\
\hline $\begin{array}{c}\text { Photosynthetic } \\
\text { Activity }\end{array}$ & N.S. & -- & ${ }^{* *}$ & -- & N.S. & -- \\
\hline
\end{tabular}

Statistical treatments, where relevant, the experimental data subjected of One, two, and three - Way analysis of variance (ANOVA).

Note: $\mathrm{F}$ values ${ }^{*}=\mathrm{P}<0.05, \quad{ }^{* *}=\mathrm{P}<0.01,{ }^{* * *}=\mathrm{P}<0.001$ and N.S. $=$ Not Significant. CO: Concentrations, TR: Treatments (SS) \&(SS/HP - "V/V"), ST: Stages of growth.

Conclusions: The resulted presented here indicate that, generally, salinity treatments reduced grain germination, plant growth, dry weight, succulence, mitotic index, yield production, chlorophyll content (chl, $a+b)$, carotenoids and photosynthetic activity increased under salinity stress. The effects of incorporating a hydrogel polymer into sand on development of selected maize (Zea mays, L.) grown under saline conditions has been demonstrated. The grains of maize were germinated in sand/ hydrogel polymer mixture $(80: 20 \mathrm{v} / \mathrm{v})$ with added Hoagland nutrient solution, then transplanted after 7 days from germination into a range of sand/swollen hydrogel polymer $(90: 10 \mathrm{v} / \mathrm{v})$ in plastic growbags. Saline solutions containing $\mathrm{NaCl}, \mathrm{CaCl}_{2}$, $\mathrm{MgCl}_{2} \quad(0.0,2,000, \quad 4,000, \quad 6,000, \quad 8,000$ ppm.) were applied to the growbags (to field capacity twice per week, alternating with a comparable watering regime. Hydrogel polymer incorporating with sand soil $(\mathrm{SS} / \mathrm{HP})(\mathrm{v} / \mathrm{v})$ reduced the effect of salinity treatments. From those results, the reduction in growth and yield production under saline stress may be due to the expenditure of energy on the synthesis of organic or inorganic components for osmotic adjustment rather than for growth. The decrease in water content may occur because plants grown in saline soil accumulate high levels of salt and an osmotic adjustment is required to maintain root water potential lower than that of the external medium.

\section{ACKNOWLEDGEMENTS:}

Appreciation is expressed to Miss Hanan Saleh Al Othaimin, for drawing the Figs., Faculty of Applied Science for Girls, University of Umm Al Qura, Makkah Al Mukaramah, Kingdom of Saudi Arabia.

\section{REFERENCES}

Abd El Rahman, S.A. (1977): Response of wheat and barley plants to salinity cycocel treatment. M.Sc. Thesis, Faculty of Agriculture, Ain Shams University, A.R.E. 
Ahmed, A. M., Heikal, M. M. and Zidan, M.A. (1980): Photosynthesis and some other growth parameters of Leguminous plants as affected by salinization treatments. Monspeliensia, Botanique, (33): 10 pp.

Albuzio, A., (1978): Effect of salinity on photosynthesis and photorespiration of two wheat species. Can. J. Bot., 56: $121-126$

Allen, S. Grimshay; H. M., Parkin Son, J. A and Quarmby, C. (1974): Chemical analysis of ecological materials. Blackwell Scientific Publications, Osney, Oxford, London, pp 565.

Aronoff, S. (1949): Photochemical reduction of chloroplast grana. Journasl of Plant Physiology, 21: 393 - 409.

Arnon, M.M. and Shavit, N. (1963): A sensitive and simple methods for determination of ferricyanide. Anal. Biochem., $6: 549$ - 554 .

Asana, R. D, and Kale, V. R. (1965): A study on salt tolerance of four wheat varieties. Indian Journal of Plant Physiology, 8:5-22.

Ashour, N. I., Abdel Halim, M. A., Raafat, A. and Nour, T.A. (1977): Increasing salt tolerance of wheat at early stages of growth under chloride and sulphate types of salinity. Acta Agronomy Academy Science Hungarian, $26: 127-134$

Ashraf, M., P.J. S. Haris, (2004): Potential biochemical indicators of salinity tolerance in plants. Plant Sci., 166, 3-16.

Ayers, A. D. and Eberhard, D. L. (1960): Response of edible broad bean to several levels of salinity. Agronomy Journal, 52 (2): 110 - 111.

Ayers, R.S. and Westcot, D.W., (1985): Water Quality for Agriculture. FAO Irrigation and Drainage Paper 29 rev. 1, Rome, 174 pp.

Bates, L. S., Waldern, R.P. and Teare, I. D. (1973): Rapid determination of free proline for water stress studied. Plant and Soil, 39 : 205 - 207.

Berlin, J. Quisenberr, J. E., Bailey, F., Woodworth, M. and Micheal, B. L. (1982): Effect of water stress on cotton leaves. 1- An electron microscopic stereological study of the palisade cells. Journal of Pant Physiology, 70: 238-243.

Bernal, C. T., Bingham, F. T. and Oerfili, J. (1975): Salt tolerance of Mexican wheat. II- Relation to variable $\mathrm{NaCl}$ and length of growing season. Soil Science American Proc. $39: 777$ - 780.

Bernstein, L. (1963): Osmotic adjustment of plants to saline media. II- Dynamic phase. Am. J. Bot., 48: 909 918.

Bernstein, L. (1974): Crop growth and salinity. Agronomy Journal, 17: 39-90.
Bor, M., F. Ozdemir, I. Turkan, (2003): The effect of salt stress on lipid peroxidation and antioxidants in leaves of sugar beet Beta vulgaris, L. and will beet beta maritime, L. Plant Sci., 64,77-84.

Bowman, W.D. and Strain, (1987): Interaction between $\mathrm{CO} 2$ enrichment and salinity stress in the $\mathrm{C} 4$ nonhalophyte Andropogon glomeratus Walter B.S.P. Plant Cell Environ., 10: 267-270.

Bliss, C. I. (1973): Plant Protection. No. 12. Leningrad.

Chavan, P. and Karadge, B. A. (1980): Influence of salinity on mineral nutrition of peanut (Arachus hypogeal, L.). Plant and Soil, 54: 5-13.

Chu, T. M., Aspinal, D. and Paleg, L. G. (1976): Stress metabolism. VIII - Specific ion effects on proline accumulation in barley. Australian Journal of Plant Physiology, 3 : $503-511$

Dahiya, S.S. and Singh, M. (1967): Effect of salinity, alkalinity and iron application on availability of iron, manganese, phosphorus and sodium in pea (Pisum sativum) crop. Plant and Soil, 44 : 697 -702.

Das, S. K. and Mehrotra, C. L. (1971): Salt tolerance of some agricultural crops during early growth stages. Indian Journal of Agriicultural Science, 41 (10) : 882 888.

Downton, W. J. S. (1977): Photosynthesis in salt stressed grapevines. Aust. J. Plant Physiology, 4 : 183 - 192.

Demiral, T. I.,Turkan, (2005): Comperative lipid peroxidation, antioxidant defense systems and proline content in roots of two rice cultivars differing in salt tolerance. Env. Exp. Bot., 53, 247-257.

Durgapras, K.M.R.,M. Muthukumarasamy,R.Paneerselvam, (1996): Changes in protein metabolism induced by salinity in soybean seedlings. Ind. J. Plant Physiol., 198-101.

Durie, R. A., Schaffer, H. N. S. and Swaine, D. J. (1965): Technical communication 47, Commonw,Sci. Industr, Res. Org. Tech. Commun. 47:33-37.

EL Sayed, Hameda, Kirkwood, R . C. and Graham, N. B. (1991): The Effect of a Hydrogel Polymer on the Growth of Certain Horticultural Crops Under Saline Conditions. Journal of Experimental Botany, vol. 42, No.( 240), pp. $891-899$.

EL Sayed, Hameda And Kirkwood, R . C. (1992): Effect of $\mathrm{NaCl}$ Salinity and Hydrogel Polymer Treatments on Viability, Germination and Solute Contents in Maize (Zea mays , L.) Pollen. Phyton Journal , Vol. 32, Fasc. (1),pp. 143-157, 27/8/1992.

EL Sayed, Hameda, Kirkwood, R . C. and Graham, N. B. (1995): Studies on the Effect of Salinity and Hydrogel Polymer Treatments on the Growth, Yield Production and Solute Accumulation in Cotton and Maize. Journal 
of King saud University, Vol.7, Agric. Sci. (2), pp,129 333 Riyadh, (A. H. 1415/1995)

El Shourbagy, M. N., El Ghonemy, A. A., Ahmed, A. M. and Hammoud, M. A. (1980): Effect of pre sowing seed treatments on growth and chemical composition of certain drought - stressed grasses. Delta Journal of Science (Cairo), 4 : 55 - 90.

El Zam, O. E. and Epstein, E. (1969): Salt relations of two grass species differing in salt tolerance. II- Kinetics of the absorption of $\mathrm{K}^{+}$and $\mathrm{Cl}^{-}$by their excised roots. Agrochemica, 13 : 196 -206.

Fallth, Othman N., Hussain, Ghulam \& Al Varado Wilso, (1988): Effect of saline irrigation on germination, growth and dry matter production of different bean cultivars. Proceeding of the Eleventh Symposium on the Biological Aspects of Saudi Arabia, Yaubu, May 30 - June 2, 1988.

Flowers, T. J., Troke, P. E. and Yeo, A. R. (1977): The mechanism of salt tolerance in halophytes. Annual Review of Plant Physiology, 28 : $89-121$.

Gama P.B., S.Inanaga, K.Tanaka, R. Nakazawa, (2007): Physiological response of common bean (Phaseolus Vulg. L.) seedlings to salinity stress. African J. of Biotechnology, vol.6 (2), 79-88.

Garsia-Sanchez, F.,J.L. Jufon, M. Carvaial, J.P. Syverstem, (2002): Gas exchange, chlorophyll and nutrient contents in relation to $\mathrm{Na}+$ and Claccumulation in 'Sunburst' mandarin grafted on different rootstocks. Plant Sci., 162, 705-712.

Gauch, H. G. and Wadleigh, C. H. (1951): The salt tolerance and chemical composition of rhodes and dallies grass grown in sand culture. Bot. Gaz. 112 : 259 -271 .

Grant, J.J., J.G. Loake, (2000): Role of reactive oxygen intermediate and cognate redox signalling in diseance resistance. Plant Physiol,124, 21-29.

Gale, J. and Poljakoff-Mayber, A. (1970): Inerrelations between growth and photosynthesis of salt bush (Atriplex halimus, L.) grown in saline media. Aust. J. Biol. Sci. 23 : 937 - 945

Graham, N. B. , Nwachuku, N. E. and Walsh, D. T. (1982): Interaction of (Polyethylene oxide) with solvents ; 1Preparation and swelling of a crosslinked poly(ethylene oxide) hydrogel polymer, J. 23,pp. 1345 -1349 .

Greenway, H., Gunn, A. and Thomas, D. A. (1966): Plant response to saline substrates. VIII- Regulation of ion concentration in salt sensitive and halophytic species. Aust. J. Biol. Sci., 19 : 741 - 756.

Guggenheim, J. and Waisel, Y. (1977): Effect of salinity, temperature and nitrogen fertilization on growth and composition of Rhodes grass (Chloris gayana, Kunth.). Plant and Soil, 47 : 431 - 440.

Hajrasuliha, S. (1980): Accumulation and toxicity of chloride in bean plants. Plant and Soil, 55: $133-138$.

Helal, H. M. and Mengel, K. (1981): Interaction between light intensity and $\mathrm{NaCl}$ salinity and their effects on growth, $\mathrm{CO}_{2}$ assimilation, and photosynthate conversion in young broad beans. Journal of Plant Physiology, 67: 99 - 102.

Hernandez, J.A., P. Mullineaux , F. Sevilla, (2000): Tolerance of pea (Pisum sativum L.) to long term stress is associated with induction of antioxidant defences. Plant Cell Environ., 23, 853-862.

Itai, C., Richmond, A. and Vaadia, Y. (1968): The role of root cytokinins during water and salinity stress. Israel Journal of Botany, 17: 187 - 195.

Jackson, W. A. and Thomas, G. W. (1960): Effect of KCl and dotometric limestone on growth and ion uptake of sweet potato. Soil Sci. $89: 347$ - 352.

Jacoby, B. (1961): Calcium/magnesium ratio in the soil medium as related to magnesium uptake by citrus seedlings. Plant and Soil, $15: 17$.

Johnson and Ulrich, (1959): Analytical methods for use in plant analysis. U.S. Dept. Agric.California University. Agriculture, Information, Bulletin, 766.

Joolka, N. K., Singh, J. P. and Khera, A. P. (1977): Mineral composition of grape as affected by chloride and sulphate salts of sodium in soils. Indian Journal of Agric. Sci., $47: 201-203$.

Katerji, N., J.W. van Hoorn, A. Hamdy, N. Bouzid,, S. ElSayed Mahrous and M. Mastrorilli (1992): Effect of salinity on water stress, growth and yield of broad beans. Agricultural Water Management, 21: 107-117

Kaymakanova, M. and Stoeva, N. (2008): Physiologicsl Reaction Of Bean Plants (Phaseolus vulgar, L.) To Salt Stress Gen. Appl. Plant Physiology, special Issue, 34 (3-4), 177-188.

Khan, M.H., S.K. Panda, (2008): Alterations in root lipid peroxidation and antioxidative responses in two rice cultivars under $\mathrm{NaCl}$-salinity stress. Acta Physyol Plant, 30: 91-89.

Khan, M.H., L.B.Singha, S.K.Panda, (2002): Changes in antioxidant levels in Oriza sativa, L. roots subjected to $\mathrm{NaCl}$-salinity stress. Acta Physyol Plant, 24: 145 -148.

Khatkar, D., M.S. Kuhad, (2000): Short-term salinity induced changes in two wheat cultivars at different growth stages. Biol. Plant., 43(4), 629-632.

La Haye, P. A. and Epstein, E. (1969): Salt toleration by plants, enhancement with calcium. Science journal, 166 " $395-396$. 
Lapina, L. P. and Bikmukametova, S. A. (1972): Effect if iso-osmotic concentrations of sodium sulphate and chloride on photosynthesis and respiration in corn leaves. Fiziol, Rast., 19 : 792 -793.

Larsen, H. (1967): Biochemical aspects of extreme halophilism. Adv. Microb. Physiol. 1, 97 -132.

Lessani, H. and Marschner, H. (1978): Relation between salt tolerance and long distance transport of sodium and chloride in various crop species. Australian Journal of Plant Physiology, 5: 27 -37.

Longstreth, D.J. and Strain, B.R., (1977): Effects of salinity and illumination on photosynthesis and water balance of Spartina alterniflora Loisel. Oecologia, 31: 191199.Physiology, $5: 27-37$.

Lowry, O. H., Rosebrough, N. J., Farr, A. . and Randail, R. T. (1951): Protein measurement with Folin Phenol Reagent. Journal of Biological Chemistry, $193: 265$ 275.

Maas, E. V., Ogata, G. and Gaber, M. J. (1972): Influence of salinity on $\mathrm{Fe}^{3+}, \mathrm{Mn}^{2+}$ and $\mathrm{Zn}^{2+}$ uptake by plants. Agron. J., 64 : 793-795.

Maas, E. V. and Nieman, R. H. (1978): Physiology of plant tolerance to salinity. Ami. Soc. Agron. Spec. Publ., 277 $-299$.

Mackinney, G. (1941): Absorption of light by chlorophyll solutions. Journal of Biological Chemistry. 140 : $315-$ 322.

Maliwal, G. L. , Sanghi, A. K., Paliwal, K. V. and Sharma, H. N. (1975): Germination capacity of some maize open pollinated varienties, inbreds, hybrids, synthetic and composite in saline substrate. Indian Journal of Agricultural Research, 9: 83 - 86.

Mandhania, S., S. Madan, V. Sawhney, (2006): Antioxidant defense mechanism under salt stress in wheat seedlings. Biol. Plant, 227, 227-231.

Mansour, M. M. F., (2000): Nitrogen containing compounds and adaptation of plants to salinity stress, Biol. Plant., 43, 491-500.

Mansour, M.M., F.Z. Salama., M. Ali, A. F. Abou Hadid, (2005): Cell and plant responses to $\mathrm{NaCl}$ in Zea Mays L. cultivars differing in salt tolerance. Gen. Appl. Plant Physiol., 31(1-2), 29-41.

Meloni, D.A., A.A.Oliva, Z.A. Martinez, J. Cambraia, (2003): Photosynthesis and activity of superoxid dismutase, peroxidase and glutathione reductase in cotton under salt stress. Environ. Exp. Bot., 49, 69-76.

Metzner, H., Rau, H. und Senger, H. (1965): Untersuchungen zur synchronisier-barkeit einzeiner pigment angelmutanten von chlorella. Planta J., 65 : 186 - 194.

Misra, A.N., S.M. Sahu, M. Misra, P. Singh , N. Das, M. Kar, P. Sahu, (1997): Sodium chloride induced changes in leaf growth and pigment and protein contents in two rice cultivars. Biol. Plant., 39, 257-262.

Mittler, R., (2002): Oxidative stress, antioxidants and stress tolerance. Trends Plant Sci., 7, 405-410.

Moore, S. and Stein, W. H. (1948): Photometric ninhydrine method for use in the chromatography of amino acids. Journal of Biological Chemistry, 176: 367.

Munnas, R. C., (2002): Comparative physiology of salt and water stress. Plant Cell Environ., 25, 239-250.Naguib, M. I. (1963): Colorimetric estimation of plant polysaccharides. Zucker, 16: 15-18.

Naguib, M. I. (1964): Effect of seven on the carbohydrate and nitrogen metabolism during germination of cotton seeds. Indian Journal of Experimental Biology, 2: 149152.

Nelson, N. (1944): A photometric adaptation for somagi method for determination of glucose. Journal of Biological Chemistry, $153-275$.

Nieman, R. H. (1962): Some effects of sodium chloride on growth. Photosynthesis and respiration of twelve crop plants. Bot. Gaz., 123 : 279 - 285.

Nieman, R. H. (1965): Expansion of bean leaves and its suppression by salinity. Plant Physiology $40: 156-$ 161.

Nieman, R. H. and Clark, R. A. (1976): Interactive effects of salinity and phosphorus nutrition on the concentrations of phosphate and phosphate esters in mature photosynthesizing corn leaves. Plant Physiology, 2 : 137 - 161.

Nieman, R. H. and Shannon, M. C. (1976): Screening plants for salinity tolerance. "Proc. Of a Workshop Plant Adaptation to Mineral Stress in Problem Soil" Publ. by Cornell Unv. Agric. Exp. Ithaca.

Osman, M. E. H., Metzner, H. and Fisher, K. (1982): Effect of nitrate on thylakoid reaction. I- Influence on photosynthetic electron transport. Phosynthetica, 16 : (1), $7-12$.

Osmond, C.B. and Greenway, H., (1972): Salt responses of carboxylation enzymes from species differing in salt tolerance. Plant Physiol., 49: 260-263.

Paliwal, K. V., Maliwal, G. L. and Manohar , S.S. (1976): Effect of the level of salinity of irrigation water on the growth and yield of barley varieties grown on a sandy soil of Rajastan. Indian Journal of Agricultural Science, 46(4): $159-164$.

Passera, C. and Ravikovitch, S. and Porath, A. (1967): The effect of nutrients on the salt tolerance of crops. Plant and Soil, $26: 49-71$.

Rains, D. W. (1972): Salt transport by plants in relation to salinity. Annual Review of Plant Physiology, 23: 367 388. 
Ravikovitch, S. and Yoles, D. (1971): The influence of phosphorus and nitrogen on millet and clover growing in soils affected by salinity. I- Plant development. Plant and Soil, $35: 555-567$.

Richards, L. A. (1954): Diagnosis and improvement of saline and alkali soil, (ed.) U.S. Salinity Laboratory. U. S. Dept. Agric. Hand Book 60.

Robinson, P. S. (1985): Osmotic adjustment by intact isolated chloroplasts in response to osmotic stress and its effect on photosynthesis and chloroplast volume. Journal of Plant Physiology, 79 : 996 - 1002.

Samenia, A. N., Mafton, M., Bassiri, A. and Sepaskhah, A. R. (1980): Growth and chemical composition of dry beans as affected by soil salinity and $\mathrm{N}$ fertilization. Plant and Soil, 54: 217 - 222.

Santarius, K. A. (1973): The protective effect of sugars on chloroplast membranes during temperature and water stress and its relationship to frost, desiccation and heat resistance. Planta, 113: $105-114$.

Sanjeeva Reddy, M. (1967): Metabolism of chloroplasts isolated from leaves of groundnut plants (Archis hypogea, L.) grown in normal, salinized and alkalized soils. Thesis approved by S.V. University Tirupati, India.

Sayed, M. M. and Swaify, S. A. E. (1972): Effect of saline water irrigation on N. Co. 310 and H. 50.7209 cultivars of sugarcane. II- Chemical composition of plants. Trop. Agric. $50: 45-51$.

Sekine, T. Sasakawa, Morita, S., Kimara, T. and Kuratomi, K. (1972): Cf. Laboratory Manual for Physiological studies of Rice Eds. S. Yashida, D. Foeno, J. N. Cook and K. A. Gomez, Publ. by International Rice Research Institute Manila.

Shannon, M., (1984): Breeding, selection and the genetics of salt tolerance. In Salt tolerance in Plants. Strategies for Crop Improvement, eds. Staples RC, GH Toenniessen, Wiley, New York, pp. 300-308.

Snedecor, G. W. and Cochran, W. B. (1967): Statistical Methods. $6^{\text {th }}$ Ed. Lowa State University Press.

Stepien, P., G. Klobus, (2006): Water relations and photosynthesi in Cucumis sativus, L. leaves under salt stress. Biologia Plantarum, 50(40), 610- 616

Stewart, G. R. and Lee, J. A. (1974): The role of praline accumulation in halophytes. Planta, $120: 279-289$

Strack, Z., Karwowska, R. and Kraszeweka, E. (1975): The effect of several stress conditions and growth regulators on photosynthesis and translocation of assimilates in the bean plant. Acta Soc. Bot. Pol., 44 : $567-588$.

Storey, R. and Wyn Jones, R. G. (1975): Betaine and chlorine levels in plants and their relationship to $\mathrm{NaCl}$ stress. Plant Science Letters, 4: 161 -168.
Strogonov, B.P. (1964): Physical basis of salt tolerance of plants. Academie Science USSR, Davey and Co. New York.

Strogonov, B.P. (1970): Structure and function of plant cells in saline habitats. Israel Programme for Scientific Translation. Jerusalem.

Taleisnik-Gertel, E., Tal, M. and Schannon, M. C. (1983): The response to $\mathrm{NaCl}$ of excised fully differentiated and differentiated and differentiating tissues of the cultivated tomato (Lycopersicon esculentum) and its wild relative, $L$. peruvianum and Solanum pennellii, Physiologia Plantarum, 59: 659 - 663.

Tourneux, C., G Peltier, (1995): Effect of water deficit on the photosynthetic oxygen exchange measured using 1802 and mass spectrometry in Solanum tuberosum leaf disks. Planta, 195, 570-577.

Thenabada, M. W. (1966): Magnesium nutrition of cotton as influenced by sodium. Soil and Fertilizers, 29: 288.

Thenabada, M. W. (1968): Magnesium-sodium interactions affecting the uptake and distribution of potassium and calcium by cotton. Plant and Soil, 29 (1) $132-143$ (Eng.) (c.f. Chemical Abstract, $70: 28-38$.

Van Hoorn, J.W., (1991): Development of soil salinity during germination and early seedling growth and its effect on several crops. Agric. Water Manage.,20:1728.

Venkataraman, K. V. and Tejwarri, K. G. (1961): Further studies on the nutritional balance in Fluecured tobacco: Interrelationship between cations accumulated in the leaves. Soil Science, 91: 324.

Volhard, A. (1956): Chlorides. In Modern Methods of plant Analysis Eds. K. Peach and M. V. Tracey. SpringerVerlag Publ. Berlin 1, Pp 487.

Weimberg, R. (1970): Enzyme levels in pea seedlings grown on highly salinized media. Plant Physiology, 46 : $466-470$.

West, D.W., Hoffman, G.J. and Fisher, M.J., (1986): Photosynthesis, leaf conductance and water relations of cowpea under saline conditions. Irrig. Sci., 7: 183193.

Udovenko, G. U.., Semushina, L. A. and Petrochenko, N. G. T. (1971): Character and possible explanation of the changed photosynthetizing activity of plant during salinization. Fiziol, Rast. $18: 708$ - 715.

Ya, P. L. and Tunekazu, T. (1966): An improved colorimetric determination of amino acids with the use of ninhydrin. Anal. Biochem., $14: 71$ - 77.

Yeo, A.R., Caporn, S.J.M. and Flowers, T.J., (1985): The effect of salinity upon photosynthesis in rice (Oryza sativa L.). Gas exchange by individual leaves in relation to their salt content. J. Exp. Bot., 36: 12401248. 